\title{
O corpo nas artes visuais: entrecruzamentos na formação inicial em educação especial ${ }^{1}$
}

Thais Raquel da Silva Paz ${ }^{2}$

Viviane Diehl ${ }^{3}$

\section{Resumo}

O presente artigo é parte da pesquisa realizada com um grupo de docentes em formação inicial, do curso de Educação Especial, da Universidade Federal de Santa Maria, RS. Compreendendo o corpo como um dispositivo capaz de suscitar a reflexão sobre as artes visuais e o contexto das colaboradoras, foram realizadas propostas no intuito de problematizar e compreender como elas podem (re)construir suas subjetividades docentes a partir da educação em artes visuais. Os autores BARBOSA (2003); GREINER (2008); HERNÁNDEZ (2010); LARROSA (2002); LOPONTE (2007); MARTINS (2009); OLIVEIRA (2009), dentre outros, contribuíram com a tessitura teórica desta pesquisa. Ao procurar conhecer sobre o potencial da educação das artes visuais na (re) conceituação da formação docente foi possível compreender a importância de uma experiência que nos passe, nos toque e nos aconteça, reverberando na constituição da formação de cada uma das colaboradoras da pesquisa.

Palavras-chave: Formação docente; Cultura visual; Corpo.

\begin{abstract}
This article is part of the research that was configured as a proposed approach in visual arts with an experienced group of teachers in initial training course for Special Education, Federal University of Santa Maria, RS. With the understanding of the body as a device capable of giving rise to a reflection on visual arts and the context of the collaborators some proposals were made in order to discuss and understand how they can (re)construct their teaching subjectivities from an education in visual arts. The authors BARBOSA (2003); GREINER (2008); HERNÁNDEZ (2010); LARROSA (2002); LOPONTE (2007); MARTINS (2009); OLIVEIRA (2009), among others, contributed with the theory support. In seeking an understanding about the potential of visual arts education in the (re)conceptualization of teacher training of the collaborators in this research, it was possible to realize the importance of an experience that may touch and constitute us, reverberating in the constitution of the formation of each collaborator.
\end{abstract}

Keywords: Teacher training; Visual culture; Body.

As considerações tecidas no decorrer deste artigo fazem referência à pesquisa desenvolvida durante o curso de Licenciatura em Artes Visuais no ano de 2010, como requisito parcial de conclusão do curso. O principal objetivo da pesquisa foi compreender a contribuição das artes visuais, a partir da contextualização das práticas de ver e as formas de apresentação do corpo, para a formação inicial em educação especial.

\footnotetext{
${ }^{1}$ Artigo produzido a partir da pesquisa "O corpo nas artes visuais como dispositivo para a (re) conceituação da formação docente inicial - um estudo com acadêmicas do curso de educação especial", realizada para o Trabalho de Conclusão de Curso em Artes Visuais - Licenciatura Plena em Desenho e Plástica sob orientação da Profa. Ms. Viviane Diehl.

${ }^{2}$ Licenciada em Artes Visuais pela Universidade Federal de Santa Maria/RS. Bolsista PROLICEN 2008. Bolsista PIBIC/CNPq 2009/2010. Membro do GEPAEC - Grupo de Estudos e Pesquisas em Arte, Educação e Cultura, diretório CNPq.

${ }^{3}$ Mestre em Educação pela UPF. Docente do curso de Artes Visuais da UFSM, Arte-educadora e assessora do Curso de Artes Visuais da UNOESC-SC, coordenadora do Projeto de Alfabetização estético-cultural. Artista Plástica do Atelier Vivie Diehl.
} 
A pesquisa foi realizada a partir da abordagem metodológica qualitativa, em que a observação participante tornou-se de fundamental importância, pois, como destaca Chizzotti (1998), os indivíduos para a pesquisa qualitativa são reconhecidos por elaborarem conhecimentos, e o significado que estes dão às coisas e à sua vida são focos de atenção especial pelo pesquisador. Os meios para a organização das informações devem ter relações diretas com o ambiente natural da pesquisa, onde o indivíduo em seu contexto será o principal colaborador para apresentar dados relevantes. Desta forma, busquei levantar informações por meio de entrevista aberta e semi-estruturada, de compreensões documentais como textos, imagens e vídeo, e do diário de campo escrito após cada encontro com as colaboradoras.

O trabalho foi realizado com quatro acadêmicas do 5 은 semestre do curso de Educação Especial da Universidade Federal de Santa Maria (UFSM/RS) que durante o período da pesquisa cursavam a disciplina Artes visuais e Educação especial (MEN 1077 - T. 12). Foram realizados seis encontros, que aconteceram no Laboratório de Artes Visuais, sala 3366 do Centro de Educação, na UFSM/RS. Estes encontros abordaram as temáticas: corpo e artes visuais, propondo reflexões e diálogos com a educação especial e formação docente.

Ao buscar compreender como as colaboradoras da pesquisa percebiam inicialmente a arte na educação, surgiram comentários como:

A arte, na minha visão, sempre foi mais terapêutica... Até pelas aulas que tive na infância, que eram mais para lazer... A pintura é a arte mais comum... eu achava que estamparia, serigrafia, não era arte.

Muitas vezes, as aulas de artes visuais são vistas como sinônimo de entretenimento e terapia e, ao pensar sobre isso concordo com Barbosa (2003, p.21) quando ela diz que

aqueles que defendem a arte na escola meramente para liberar a emoção devem lembrar que podemos aprender muito pouco sobre nossas emoções se não formos capazes de refletir sobre elas. (...) Se a arte não é tratada como um conhecimento, mas somente como um 'grito da alma', não estaremos oferecendo uma educação nem no sentido cognitivo, nem no sentido emocional.

Mas é importante levar em consideração o que dizem as colaboradoras, pois tanto as artes visuais como a sua inserção na educação escolar passaram por constantes transformações. Provavelmente elas venham de uma educação das artes visuais que priorizava questões relevantes na época, mas que hoje não dão mais conta pelo contexto 
em que vivemos. Sendo necessário então propor um olhar diferenciado do senso comum, como pode nos propor refletir o poema de Manoel de Barros Uma didática da invenção:

Desaprender oito horas por dia ensina os princípios [...]

As coisas não querem mais ser vistas por pessoas razoáveis:

Elas desejam ser olhadas de azul - que nem uma criança que você olha de ave (BARROS apud CANTON, 2009, p.12).

Penso, a partir disso, que a educação não poderia ser olhada de forma razoável, intacta, pronta. Ao desaprendermos cotidianamente, buscamos um olhar curioso em cada detalhe desse mundo e conhecimentos que se transformam a cada instante, reinventando formas de olhar, perceber e se relacionar com essas mudanças.

Nesta pesquisa, proponho um olhar a partir das artes visuais, que é o contexto do qual falo, pensando como o corpo vem sendo trabalhado pelos artistas na contemporaneidade e que possíveis entrecruzamentos podem acontecer no campo da educação especial.

\section{O corpo na contemporaneidade e as artes visuais}

O conceito de corpo nesta pesquisa foi pensado a partir de Christine Greiner (2008), que contribui no sentido de pensar o corpo como uma forma de organização, resultado de cruzamentos entre ambiente, informações e sujeito. Desta forma, surge nesta pesquisa como potencial para discutir a diferença de um ponto de vista cultural e social.

A presença do corpo na arte é algo que perpassa toda a existência do ser humano como produtor e criador ao longo da história, sendo que, na pós-modernidade podemos dizer que o corpo volta a ser tema central da narrativa humana. Christine Greiner, em seu livro O corpo - Pistas para estudos indisciplinares (2008), fala sobre a freqüência que tem sido ouvir que o corpo finalmente está sendo lembrado depois de séculos de esquecimento. Porém a autora deixa claro, e eu concordo com ela, que não é possível dizer com tanta conviç̧ão que o corpo tenha sido totalmente esquecido alguma vez, seja do ponto de vista da investigação teórica ou ao que se refere às experiências individuais. Pois todos nós possuímos corpos e, de alguma forma, o "entre-lugar"4 no qual as pessoas se localizam atribuem a eles significados, mesmo que não tenhamos completa consciência disso. Neste sentido, o corpo foi e continua sendo apresentado por meio de símbolos e vestígios, nas mais diversificadas linguagens. Falar do corpo é falar da própria história da arte, porque ela sempre tratou do corpo dos que a constituíram.

\footnotetext{
${ }^{4}$ O conceito de "entre" utilizado nesta pesquisa é pensado a partir de Bhabha (1998), que trata os "entrelugares" como terrenos para a elaboração de estratégias de subjetivação (singular ou coletiva) que dão início a novos signos de identidade. Interstícios é o lugar em que as experiências intersubjetivas e coletivas de nação, o interesse comunitário ou o valor cultural são negociados.
} 
Se a história do corpo está relacionada à história da arte, pois toda expressão está ligada à materialidade, o corpo, neste contexto, pode estar representado "figurativamente, aos pedaços, residualmente, metafórica ou iconicamente, ou seja, até mesmo como uma possibilidade e não como existente" (GREINER, 2008, p.112). Podendo então ser pensado como ausência, como fazia a artista Ana Mendieta (Figura 01), que cavava buracos simulando o corpo no meio de diversos lugares e os fotografava; e, também, na obra da artista Claudia Casarino (Figura 02), em que a presença das vestes nos remete ao corpo mesmo que ele não esteja ali materializado.

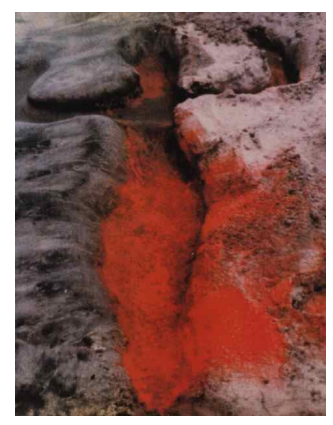

Figura.01: Silhueta no México, (1973/78)

Obra de Ana Mendieta.

Fonte: http://www. virginiamiller.com/exhibitions/1990s/AnaMendieta.html

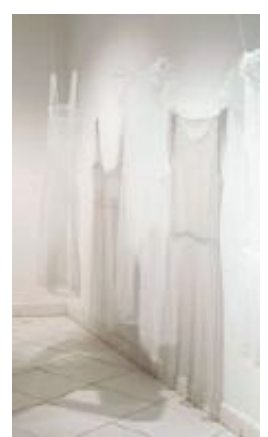

Figura.02: Sem título, obra de Claudia Casarino. Objeto/Instalação (detalhe), 2005.

Fonte: http://claudiacasarino.com/index.html

O corpo (matéria ou subjetivo) está sempre sendo (des)construído/ transformado no decorrer da história, não havendo por tanto um corpo ou uma teoria do corpo, pois o corpo assim como as subjetividades é demarcado por uma série de tratamentos que os produzem e os desfazem incessantemente. No entanto, é necessário entender que o corpo não pode ser compreendido como um produto pronto e que “(...) muda de estado no momento em que ocorre uma ação. Este é um processo complexo que começa antes mesmo de se organizar uma representação passível de reconhecimento" (GREINER, 2008, p.36). Segundo a autora, toda informação que chega ao corpo entra em 
negociação com as que já estão ali, sendo ele então fruto dos cruzamentos e não um lugar onde as informações são recebidas.

Nenhum aspecto do corpo humano pode ser considerado exclusivamente natural, pois mesmo o corpo nu, sem nenhum adereço, já é efeito da cultura. É possível falar de um corpo sem artifícios, que não possui tintura nos cabelos, nem maquiagem, mas ainda assim não será natural, pois existe uma espécie de contaminação simultânea entre esses dois sistemas simbólicos (corpo e cultura) onde ambos trocam informações de forma a se construir em processo, juntos.

As constantes transformações no campo da comunicação, da estética e da tecnologia alteram as formas de percepção do mundo e do corpo. A atitude do corpo resulta em uma situação, uma existência individual e singular, que constrói uma aparência em um tempo e lugar, caracterizando uma identidade social que contribui para o coletivo.

O corpo na contemporaneidade e as inquietações geradas por ele ocupam lugar especial de discussão em vários campos, como artes visuais, fotografia, ciência, tecnologia, etc. A essência do corpo emerge a superfície tanto nos meios de comunicação como na arte, e tem sua visualidade evidenciada.

$\mathrm{Na}$ contemporaneidade podemos falar de um corpo que está cada vez mais sentindo a necessidade de ter sua imagem transformada. Na prática artística esse corpo contemporâneo, como não podia deixar de ser, ocupa lugar importante por ser ele a assegurar a visão do imediatismo dos acontecimentos na sociedade. Neste sentido temos como exemplo as artistas Nazareth Pacheco, Vanessa Beecroft, Eunice Orlan, Cindy Sherman, entre outros, que em seus trabalhos pensam sobre questões referentes ao corpo, que inquietam a sociedade e estão sendo discutidas em diversos campos teóricos na contemporaneidade.

Nazareth Pacheco e Orlan tratam da modificação do corpo (matéria); na primeira este desejo que torna necessário submeter o corpo a cortes e perfurações aparece através dos materiais utilizados nas vestes produzidas (Figura.03), enquanto a segunda trabalha com performances, onde seu próprio corpo encarna e molda diferentes personagens, esculpindo na sua própria carne, agindo sobre ela através de cirurgias plásticas (Figura.04). 


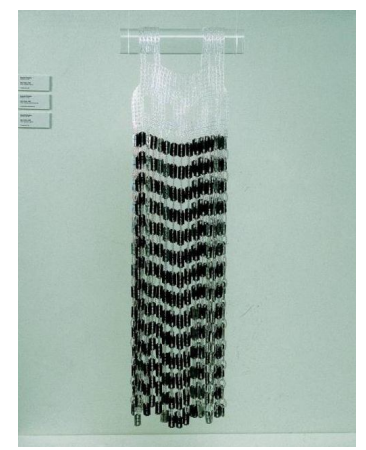

Figura.03: Nazareth Pacheco, Sem título. Cristal, lâmina de barbear e miçanga, 1997. Acervo MAM-SP.

Fonte:

http://www.muvi.advant.com.br/artistas/n/nazareth_pacheco/nazareth_pacheco.htm
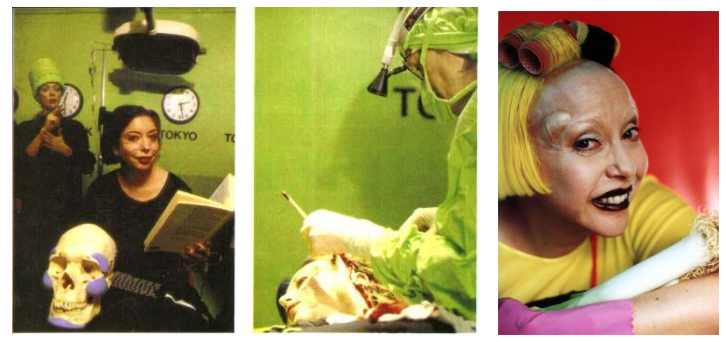

Figura.04: Eunice Orlan, Performance.

Fonte: http://omnia-mecum-porto. blogspot.com/2009/01/em-2009.html

Já Vanessa Beecroft e Cindy Sherman nos convidam a pensar a partir de suas obras sobre a padronização do corpo feminino. Beecroft (Figura.05), em suas performances, normalmente nos apresenta mulheres esguias e de aparências semelhantes, nuas e imóveis, quase como manequins. Sherman (Figura.06), apesar de não considerar seu trabalho feminista, em muitas de suas séries suscita uma reflexão sobre os estereótipos das mulheres do cinema, televisão e revistas.

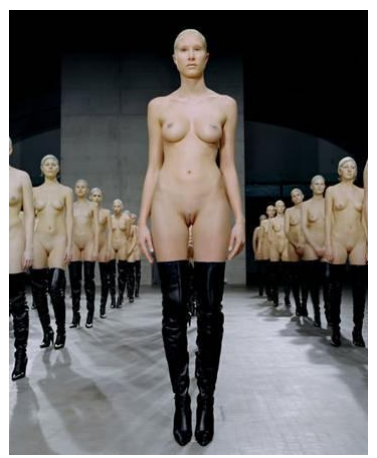

Figura.05: Vanessa Beecroft, vb 45. Performance (detalhe), 2001.

Fonte: http://www. vanessabeecroft.com 


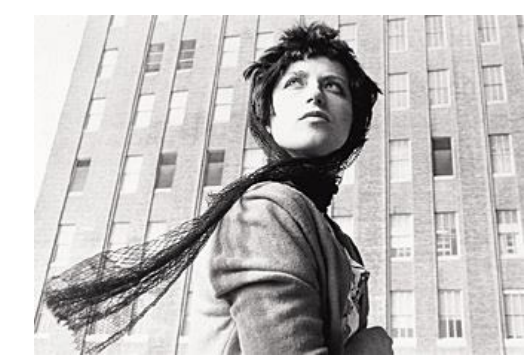

Figura.06: Cindy Sherman, Untitled Film Still \#58, 1979. Série Untitled Film Stills (Cenas de um filme sem título).

Fonte: http://www.cindysherman.com/art.shtml

No dia-a-dia, o estético pode ter ligação direta com o corpo do indivíduo, com a maneira dele aparecer, de se vestir, de se movimentar, como se o corpo fosse aquilo que estabelecesse as relações entre o sujeito e o mundo. Atualmente a palavra "diferente" passa a ser encarada como um adjetivo; e a subjetividade torna-se bastante assimilada ao corpo como um todo, "talvez a idéia de que a aparência revelaria a essência proporcione ao suj eito certa ilusão de diferenciação e distinção, em meio a um tempo e espaços massificados" (MESQUITA, 2004, p. 67). Subjetividade e corpo devem ser compreendidos nesta pesquisa como campos entrelaçados, onde o "corpo é o lugar onde a subjetividade é concretamente materializada ou, poderíamos dizer encarnada" (MESQUITA, 2004, p.59).

A subjetividade que aqui me refiro parte de Deleuze (2001), que diz respeito ao sujeito como um movimento de desenvolver-se a si mesmo. Enquanto um indivíduo que crê e inventa, (re) conceituando sua existência social e cultural cotidianamente. Dessa forma, as subjetividades pensadas nesta pesquisa estão intrinsecamente relacionadas à imagem de um corpo durante $o$ ato de perceber e de responder ao que está externo, podendo surgir de qualquer cérebro capaz de construir uma representação, por mais simples que seja de si mesmo e de seu contexto, criando e transformando essas imagens.

$\mathrm{Na}$ contemporaneidade, mais do que nunca, é pelo corpo que somos julgados e classificados, ele possui sentido emblemático, a identidade de cada sujeito. Segundo Silva (2000) a identidade é marcada por meio de símbolos, que representam uma determinada cultura e que ao mesmo tempo a difere das demais. A identidade nada mais é que uma condição alcançada pelas distinções dela com as demais. Ela existe pela negação de que não exista qualquer similaridade com os demais grupos.

A forma como representamos esse corpo, sob o olhar do outro que nos vê, traduz nossa maneira de ser no mundo, como se o corpo não fosse nada sem o indivíduo que o habita. Assim, a auto-imagem construída pelo sujeito no decorrer de sua história traz sua marca 
de vivências refletindo também suas interações com o meio, com outros indivíduos, enquanto ser cultural e histórico como membro de um grupo social.

\section{Cultura visual e corpo nas artes visuais: outros olhares sobre a formação inicial em educação especial}

Atualmente, vivemos um momento na educação brasileira cheio de desafios, pois ao iniciar a articulação de temáticas como diversidade e inclusão, torna-se necessário refletir a formação docente e a política social e educativa. Discutir as mediações realizadas pelos professores ao trabalhar com a diversidade em sala de aula significa pensar a relevância que atribuímos aos fatores socioculturais e a história de cada um, assim como outros fatores que compreendem além da ação docente.

Fala-se muito em inclusão pela diferença, entretanto, não é necessário anulá-la e, sim, (re)conceituá-la. Para os educadores, passa a ser uma problemática significativa "pensar a diferença de um campo político, em que experiências culturais, comunitárias e práticas sociais são colocadas como integrantes da produção dessas diferenças", (FREITAS, 2008, p. 19). Se fazendo necessário então compreender que o desenvolvimento cognitivo varia de acordo com o educando e, desta forma, o educador precisa levar em consideração o desenvolvimento de cada um.

Assim, propus durante esta pesquisa, desarticular os modos das colaboradoras se relacionarem com as artes visuais, ampliando conceitos, suscitando novas experiências e provocando ruídos que produzissem sentido, a partir de discussões sobre o corpo e sua implicação no campo da educação especial. Para isso, durante o desenvolvimento da pesquisa trabalhei com a perspectiva da cultura visual enquanto um espaço de interação entre as colaboradoras da pesquisa e as visualidades propostas.

A cultura visual é um termo híbrido, reconhecida não como uma teoria, mas como um campo teórico que está sendo discutido. Um reflexo das mudanças ocorridas "desde os anos 60, por diferentes campos de conhecimento, envolvendo a história da arte, a lingüística e a crítica literária, os estudos dos meios, estudos culturais e feministas", (MARTINS, 2009, p.115). Um campo transdisciplinar, alinhado com as abordagens pósestruturalistas, em que descreve uma situação onde obras de arte se fundem com referenciais de outras disciplinas e campos, como o da psicologia, da antropologia, da história, da filosofia, etc.

Diariamente sujeitos em diferentes países e culturas olham, manipulam e se relacionam com imagens advindas de diferentes referenciais, e os significados que tais imagens 
provocam se diferenciam nessa diversidade de suportes, meios e culturas. Dessa forma, torna-se importante que a educação das artes visuais aborde estas imagens não mais como simples representações da realidade, mas como construção de novas e diferentes realidades.

Acredito que o campo da cultura visual apresenta-se como uma possibilidade de produção de narrativas, construídas a partir de visualidades e contextos culturais específicos, podendo ser pensada na formação docente por apresentar-se como um campo interdisciplinar, com momentos de rupturas, conflitos e diálogos. Esta perspectiva teórica colaborou com este trabalho no momento em que propus as colaboradoras da pesquisa um espaço para refletir sobre as formas de apresentação do corpo na sociedade contemporânea a partir de imagens da arte e da mídia. Pois, assim como afirma Hernández (2010, p. 77), a perspectiva da cultura visual "não é um quê (objeto, imagens), nem um como (método para interpretar o que vemos). É o espaço de interação entre o que vemos e o como somos vistos por aquilo que vemos".

Desta forma, a proposição das visualidades, aliada as formas de apresentação do corpo, pode ser pensada como dispositivos ${ }^{5}$ que promoveu o diálogo com o contexto e a vivências das colaboradoras, instigando reflexões e posicionamentos ao conhecer a arte e pensar sobre suas incertezas, hibridismos e rótulos.

Tendo em vista que a intenção desta pesquisa foi proporcionar a vivência da educação nas artes visuais, acredito ser importante refletir sobre a experiência. E para pensar sobre isso trago o conceito de experiência a partir de Larrosa (2002) que diz que ela é o que nos passa, nos acontece, nos toca. A experiência a que me refiro deve ser separada da informação, pois aprender não é apenas adquirir e processar informações, mas sentirse tocado por aquilo que vivenciamos.

Para isso, faz-se necessário o respeito ao tempo. Tempo para refletir, para dialogar, para experimentar, pois como define Larrosa (2002, p. 24),

a experiência, a possibilidade de que algo nos aconteça ou nos toque, requer um gesto de interrupção, um gesto que é quase impossível nos tempos que correm: requer parar para pensar, parar para olhar, parar para escutar, pensar mais devagar, olhar mais devagar, e escutar mais devagar: parar para sentir, sentir mais devagar, demorar-se nos detalhes, suspender a opinião,

\footnotetext{
5 "algo que dispara, um mecanismo de força; algo que é lançado sem uma direção específica, com diferentes forças e diferentes sentidos" (OLIVEIRA, 2009 apud ROSA, 2010, p.13). Sem direção e intensidade préestabelecida, podendo atingir de formas diversas dependendo do contexto, tocando-nos de forma a (re) conceituar nossas visões de mundo.
} 
suspender o juízo, suspender a vontade, suspender o automatismo da ação, cultivar a atenção e a delicadeza, abrir os olhos e os ouvidos, falar sobre o que nos acontece, aprender a lentidão, escutar aos outros, cultivar a arte do encontro, calar muito, ter paciência e dar-se tempo e espaço.

Assim, a experiência de pensar o corpo a partir das artes visuais, proporcionou tempo e espaço para perceber a formação docente e as incertezas vivenciadas no campo da educação especial, pois

não se trata de o professor ter conhecimento das especificidades e características das deficiências ou dos indicadores de altas habilidades/superdotação dos alunos, mas, sobretudo, de o professor ressignificar a base de sua prática educativa, ou seja, pensar o currículo, o planejamento e a avaliação sob a ótica da valorização da diversidade e do respeito à diferença", (FREITAS, 2008, p. 28).

As imagens digitalizadas de trabalhos de artistas como Nazareth Pacheco, Vanessa Beecroft, Claudia Casarino, Ana Mendieta, Eunice Orlan, Loretta Lux, dentre outros, assim como de imagens de campanhas realizadas pela Benetton (Figura.07), contribuíram para os diálogos e reflexões construídas durante a pesquisa. Essas imagens foram escolhidas por tratarem do corpo de diferentes formas e possibilidades, apresentando-se como potencial para as discussões aqui propostas.

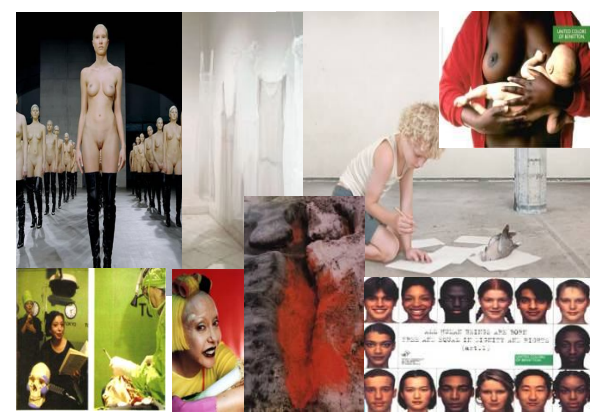

Figura.07: Colagem realizada pela pesquisadora a partir de algumas imagens das artistas citadas e da Campanha da Benetton.

Fonte: Diário visual da pesquisadora.

No decorrer dos encontros, propus um espaço de interação com algumas imagens que tratam das formas de apresentação do corpo, na arte e na publicidade, em diferentes períodos e sociedades (Figura.08). 


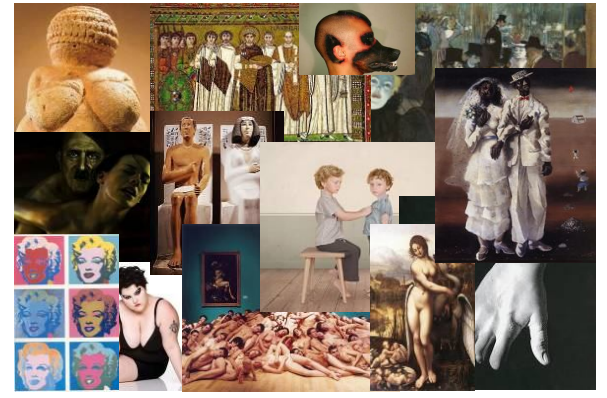

Figura.08: Colagem realizada pela pesquisadora a partir de algumas imagens visualizadas nos encontros.

I magens da arte e da mídia.

Fonte: Diário visual da pesquisadora.

As colaboradoras foram percebendo cada imagem e comentando sobre a linguagem utilizada, o artista, a propaganda, a intenção. Surpreendendo-se em alguns momentos, como no caso da obra do Ron Mueck (Figura.09), sentindo nojo (Figura.10) e, em outros, aproximando-se.

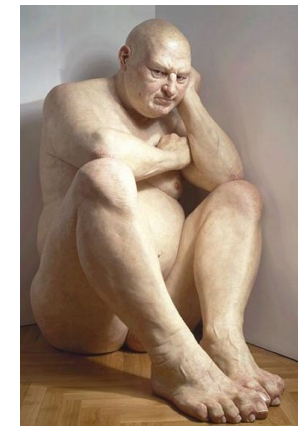

Figura.09: Ron Mueck. Big Man, 1998.

Escultura de $1,83 \mathrm{~m}$ de altura.

Fonte: http://bethccruz.blogspot.com/2009/08/obras-ron-mueck.html

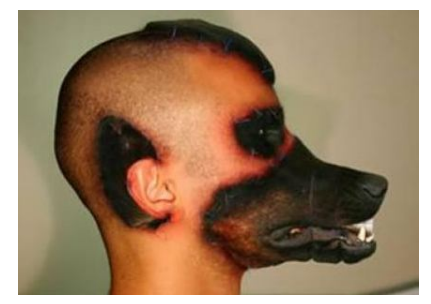

Figura.10: Rodrigo Braga, 2004.

Mescla de produção plástica e produção virtual.

Fonte: http://www.rodrigobraga.com.br/ 
A partir das imagens, as colaboradoras refletiram sobre as relações existentes entre a cultura e as representações do corpo, assim como a percepção e aproximação que acontece com determinado corpo. Pois elas mesmas percebem e comentam que existe um estranhamento com a forma que o corpo de uma criança com necessidade especial se apresenta para os demais, causando em muitos momentos afastamento e preconceito.

Pensando que "a cultura se constrói no trânsito entre o individual e o coletivo, entre dentro e fora do corpo, operando o tempo inteiro num continuum entre emoção, razão, ação corpórea", (GREINER, 2008, p. 103) podemos romper com a ideia de influência na medida em que compreendemos essa relação entre corpo e ambiente como movimentos de mão dupla. Dessa forma, não é a cultura que influencia o corpo ou o corpo que influencia a cultura, trata-se de uma espécie de contaminação simultânea onde ambos trocam informações se construindo em processo, juntos.

As colaboradoras da pesquisa acreditam que as pessoas são julgadas pelo corpo, e principalmente por todos os acessórios que carregam com ele, seja no vestuário, adornos, etc. No entanto, chegaram ao acordo de que o corpo é importante num primeiro momento, mas depois a "essência", o que está além da materialidade do corpo é levado em consideração, pois segundo uma das colaboradoras "o corpo fala até o momento em que se interage com ele...". Ao falarem em "essência", no corpo ser muito mais que a matéria, posso pensar que se referiam à subjetividade pertencente ao dono de um corpo. Pois ela "é bastante assimilada ao corpo como um todo", (MESQUITA, 2005, p. 67) e ao contrário do que pode parecer muitas vezes ela não se encontra materializada no corpo físico, tornando-se necessário outro tipo de aproximação para conhecê-la.

Ao longo dos encontros fui retomando algumas questões que havíamos conversado, tentando relembrar as relações que juntas fomos tecendo sobre corpo, subjetividades, cultura, (pré) conceitos, etc.

A partir da imagem digitalizada da obra de Nazareth Pacheco (Figura.11), as colaboradoras refletiram sobre as necessidades do corpo, diferenças, limitações. Acreditam que "ser normal" também é ser diferente e, mesmo sendo considerados "normais" temos limitações no dia-a-dia. 


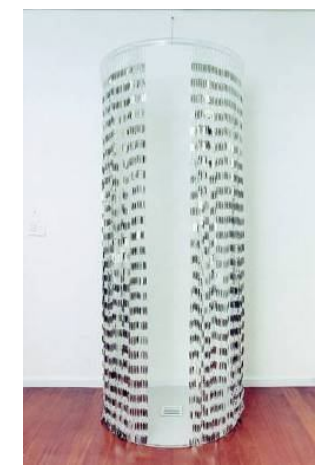

Figura.11: Sem título

Cristal, miçanga, lâmina de barbear e acrílico.

$200 \times 80 \times 77 \mathrm{~cm} .2003$.

Fonte:

http://www.muvi.advant.com.br/artistas/n/nazareth_pacheco/nazareth_pacheco.htm

A partir da proposição da construção de uma narrativa (Figura.12), abordando as questões discutidas nos encontros anteriores, as colaboradoras buscaram representar visualmente como elas vêem o corpo na sociedade contemporânea.

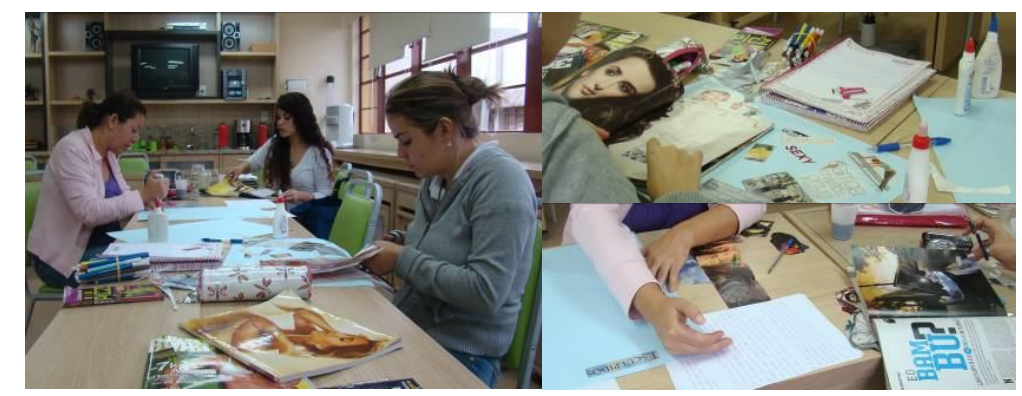

Figura.12: Colaboradoras da pesquisa produzindo suas colagens que trataram sobre suas visões de representação do corpo hoje.

Fonte: Diário visual da pesquisadora.

Ao término das colagens percebi que as colaboradoras fizeram uso de imagens e palavras (Figura.13), (re)significando essas reproduções no contexto proposto. Barbosa (1998) diz que "as relações estéticas entre a palavra e a imagem visual permeiam toda a história da arte e da literatura. Trata-se de uma relação intrínseca à natureza comunicativa da linguagem". A partir de suas narrativas compreendi o quanto as colaboradoras percebem o corpo como algo cobrado pela sociedade e pela mídia, assim como ligado aos vários relacionamentos da nossa vida, pois "o homem nunca está separado do ambiente onde vive e dificilmente pode ser compreendido sem uma atenção especial às relações que aí se organizam", (GREINER, 2008, p.23). 


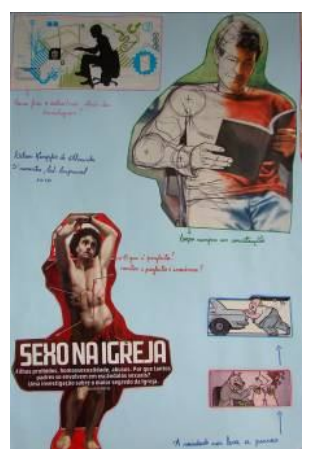

Figura.13: Colagem realizada pela colaboradora da pesquisa sobre a representação do corpo na sociedade contemporânea.

Fonte: Diário visual da pesquisadora.

O corpo, como uma forma de organização, está sempre sendo contaminado pelas diferentes culturas onde se encontra inserido. A igreja, a sociedade e a mídia, segundo as colaboradoras, possuem ação importante na constituição da cultura percebida por elas, e consequentemente no corpo. Segundo Greiner (2008), a criação de imagens; o processamento de movimentos; a organização de mediações entre o corpo, o ambiente e outros corpos; os diferentes eixos temporais que olham para o passado, o presente e têm a possibilidade de predizer o futuro; são questões que estão envolvidas nesse processamento da comunicação no e sobre o corpo.

Durante os encontros trabalhamos com outras três imagens. Uma da campanha da Benetton (Figura.14), mostrando nádegas com uma espécie de tatuagem que diz HIV positive, nos fazendo pensar sobre a possibilidade de existir algo que torne visível a situação de HIV positivo numa pessoa.

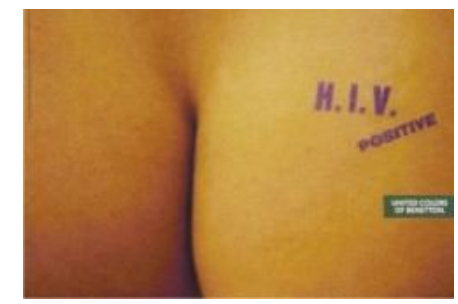

Figura.14: H.I.V. positive.

Campanha publicitária.

Fonte: http://boquiaberto. wordpress.com/2009/03/30/a-classica-campanha- benetton/ 
Outra imagem apresentou uma obra de Nazareth Pacheco (Figura.15).

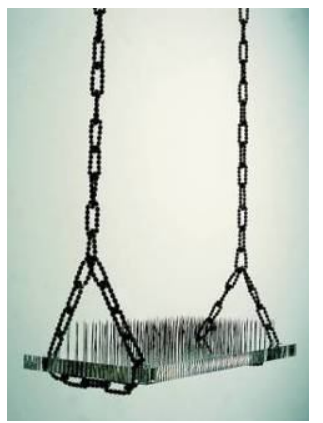

Figura.15: Sem título, 1999.

Acrílico e agulhas.

Fonte:

http://www.muvi.advant.com.br/artistas/n/nazareth_pacheco/nazareth_pacheco.htm

E apresentei, também, uma obra de Loretta Lux (Figura.16).

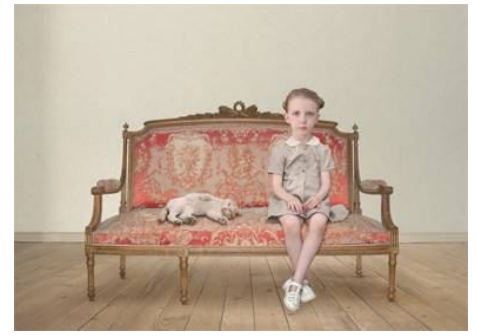

Figura.16: The girl waiting, 2006.

Fotografia.

Fonte: http://www.lorettalux.de/

Neste momento, questionei sobre o que estas imagens poderiam dizer das colaboradoras, buscando a partir delas tecer relações com o contexto profissional da educação especial. Refletiram então sobre a limitação que as duas primeiras imagens trazem, dizendo que "se tu fores o teu corpo vai sofrer com isso... tu vai sentir dor". Elas relacionam a obra da Nazareth Pacheco com a carteira de estudante, buscando problematizar a questão do sofrimento que pode ser para uma criança ser obrigada a estar sentada na sala de aula. Onde não tem o prego, mas tem a questão do incômodo, do maçante, da obrigação sem prazer para a aprendizagem.

Refletem sobre as crianças com necessidades especiais, pois algumas coisas que às vezes podia ser legal para uma criança, e por causa de "agulhas" (pessoas, sociedade, pré-conceito) as deixam em um lugar, que deveria ser confortável, desagradável. Assim como alguma limitação do corpo da própria criança, que às vezes a impede de usufruir algumas coisas. 
Sobre a obra da artista Loretta Lux, em seguida, uma das colaboradoras observa: “É estranho uma criança não querer interagir com o animal, né?". Elas pensam que a menina da obra pode ser autista. Para elas a obra remete a outra época, mais antiga, com um padrão de comportamento feminino mais reservado. Elas percebem o gato e a menina com comportamentos opostos, e até mesmo anormais, pois o gato não costuma ficar assim e nem as crianças. As colaboradoras sentiram-se intrigadas com esta obra.

Ao traduzir o título: A menina espera, pensam que talvez ela esteja esperando alguém para interagir, pois às vezes na vida escolhemos com quem nos relacionar. Para as colaboradoras a obra passa a sensação de estranheza, como elas mesmas definem. Sentem-se incomodadas pelos muitos caminhos que esta obra pode nos levar. Elas reconhecem que sentem a necessidade de entender, interpretar a obra.

$\mathrm{Na}$ continuidade dos encontros, vimos imagens digitalizadas de obras realizadas a partir das linguagens da intervenção (Figura.17) e da performance (Figura.18), dialogamos sobre alguns conceitos e fomos conversando a cada imagem.

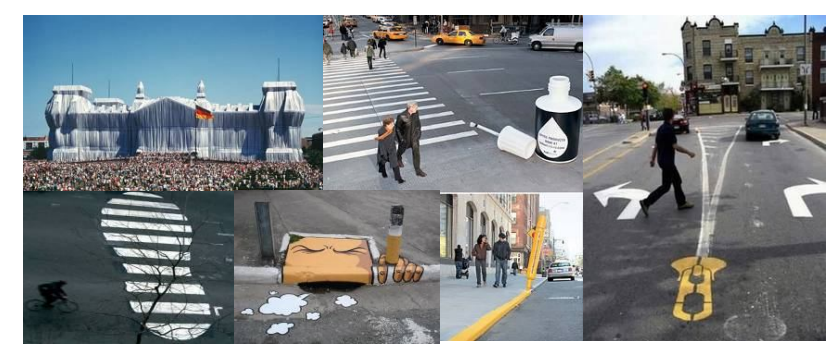

Figura.17: Colagem realizada pela pesquisadora com imagens mostradas no encontro.

Imagens de intervenção.

Fonte: Diário visual da pesquisadora.

As colaboradoras gostam das intervenções ${ }^{6}$ e comentam sobre já terem visto algo parecido na televisão e, também nas aulas de Artes visuais e Educação especial (disciplina que estavam cursando naquele período).

Ao ver as imagens de performances ${ }^{7}$, ficam horrorizadas com a performance da Eunice Orlan que faz cirurgias no próprio rosto.

\footnotetext{
${ }^{6}$ Intervenção urbana é o termo utilizado para designar os movimentos artísticos relacionados às intervenções visuais realizadas em espaços públicos. No início, um movimento underground que foi ganhando forma com o decorrer do tempo e se estruturando. Particulariza lugares recriando paisagens. Existem vários tipos de intervenções, desde pequenas inserções até grandes instalações artísticas.

${ }^{7}$ A performance é uma linguagem artística interdisciplinar, que pode combinar teatro, música, poesia ou vídeo. Normalmente segue um "roteiro" previamente definido, podendo ser reproduzida em outros momentos e locais. É realizada para um público quase sempre restrito ou ausente, dependendo assim de registros (através de fotografias, vídeos e/ou memoriais descritivos) para se tornar conhecida.
} 


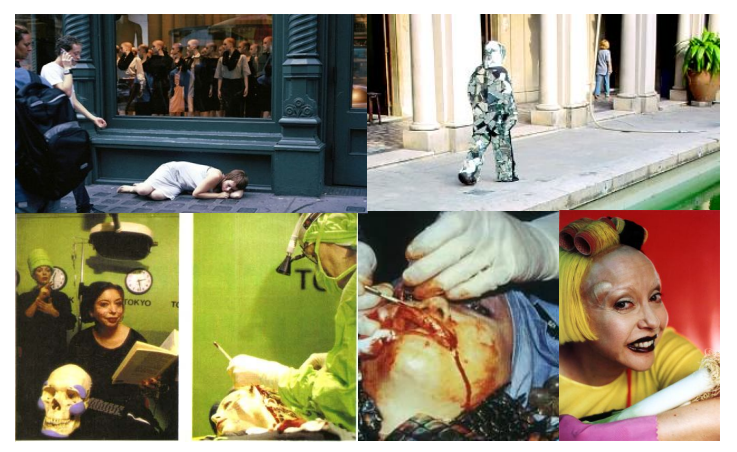

Figura.18: Colagem realizada pela pesquisadora com imagens mostradas no encontro.

Imagens de performance.

Fonte: Diário visual da pesquisadora.

Comentam sobre a performance "Locais" (Figura.19), questionando se aqueles que estão atrás da vitrine estão participando, respondo que não, pois são manequins da loja. $\mathrm{Na}$ proposta artística desta performance, a autora se retrata dormindo em diferentes locais como em frente da vitrine na loja Prada, na estação de metrô em Nova York ou no lobby de um centro de convenções, refletindo sobre a indiferença das pessoas no entorno.

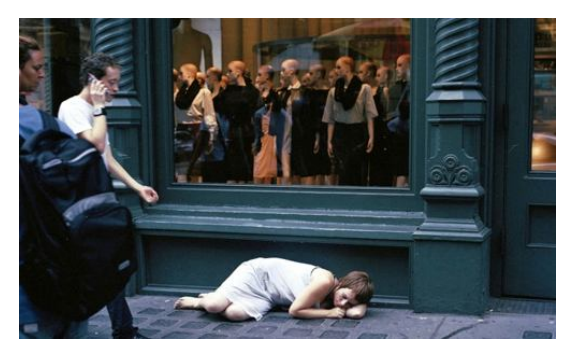

Figura.19: Obra Locais. Performance.

Fonte: www.lillymcelroy.com

Visualizamos mais algumas imagens e vídeos das performances dos artistas Vanessa Beecroft e Cauê de Camargo (formado pelo curso de Artes visuais da UFSM), que estão disponibilizados no site Youtube. Ficaram surpresas com esses tipos de trabalhos artísticos.

Percebo que um dos grandes obstáculos para que as colaboradoras se aproximem da arte contemporânea, é o fato desta ter se tornado parecida demais com a vida. $\mathrm{Na}$ contemporaneidade as situações cotidianas são muito exploradas como potencial artístico, o que acaba por nos confundir em muitos momentos, pois a arte 
contemporânea não se preocupa em proteger o campo da arte das infiltrações de elementos de outros campos do conhecimento como fez a arte moderna, pelo contrário,

esparramou-se para além do campo especializado construído pelo modernismo e passou a buscar uma interface com quase todas as outras artes e, mais, com a própria vida, tornando-se uma coisa espraiada e contaminada por temas que não são da própria arte, (COCCHIARALE, 2006, p.6).

As artes visuais, neste sentido, provocam a pensar a educação de um ponto de vista em que não existem certezas nem purezas, muito menos códigos a serem decifrados. Especialmente a arte contemporânea, pois ela nos convida para um jogo em que as regras não são lineares, mas desdobradas em organizações de relações possíveis ou não de serem estabelecidas. Penso que a docência pode aprender com a arte a partir do momento em que as colaboradoras compreendem a existência de diferentes formas de se perceber, pois, a partir de uma obra ou vivência, cada indivíduo pode construir cenas particulares que apresentam a forma individual de recolher os vestígios de determinada experiência.

Retomando minha proposta de uma educação das artes visuais a partir da cultura visual, percebo que questionei os limites nas artes visuais ao mostrar a elas as diferentes linguagens, meios, formas de se produzir e perceber a arte. E, acima de tudo, problematizei a importância do visual e das formas de ver na sociedade contemporânea. Aproximando, dessa forma, as colaboradoras dessas novas realidades a partir de uma perspectiva de reflexão e reconstrução das próprias referências culturais e dos modos de ver e de serem vistas. Uma reconstrução que acontece a partir do momento presente, dando ênfase às formas de representação e à produção de novos saberes sobre essas experiências.

\section{Vivenciando a experiência segundo Larrosa (2002)}

A partir do momento em que as colaboradoras tomam conhecimento da performance como linguagem artística, surge então a intenção de experimentar o corpo nas artes visuais propondo um diálogo com questões presentes no campo da educação especial, pensando sobre o senso comum que se tem sobre as pessoas com necessidades especiais. Comentamos sobre reflexões a respeito das pessoas que usam cadeira de rodas e são discriminadas, rotuladas como cadeirantes, como se ela perdesse sua personalidade e até mesmo sua identidade por causa disso, sendo que, ser cadeirante também é sua identidade. $\mathrm{E}$ isso, para elas, acontece com o cego e com o surdo. 
Ao abordar através da performance o corpo deficiente, as colaboradoras relacionam a educação especial, que é o contexto em que elas estão inseridas, com as artes visuais, promovendo um trabalho que fecha provisoriamente as discussões realizadas durante os encontros. Refiro-me a um fechamento provisório por que acredito que de alguma forma essas discussões continuarão a reverberar em muitos outros momentos da vida acadêmica e pessoal, tanto minha como das colaboradoras.

A performance (Figura.20, 21, e 22) foi realizada no campus da Universidade Federal de Santa Maria/RS e no centro da cidade de Santa Maria/RS. Os registros foram realizados por mim e pelas demais colaboradoras.
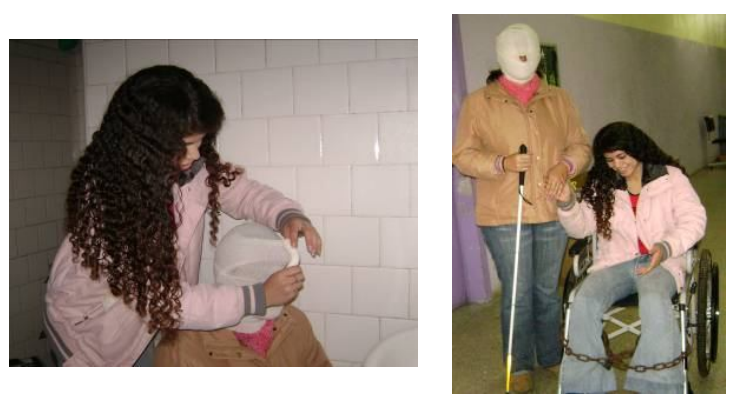

Figuras.20: Registro fotográfico da performance de 12/05/2010.

Fonte: Diário visual da pesquisadora.

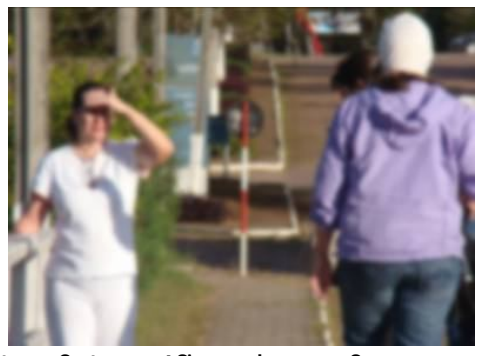

Figura.21: Registro fotográfico da performance de 21/05/2010.

Fonte: Diário visual da pesquisadora.

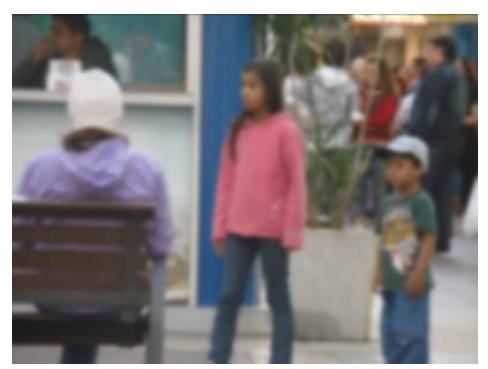

Figura.22: Registro fotográfico da performance de 21/05/2010.

Fonte: Diário visual da pesquisadora. 
Durante a realização da performance, duas colaboradoras tiveram a experiência de perceber através do próprio corpo a situação vivenciada pelo cego e pelo cadeirante. Causaram estranhamento, provocando também a caridade das pessoas. As colaboradoras puderam sentir que as pessoas querem ajudar, porém na maioria das vezes não sabem como. E que, realmente, existem muitas dificuldades para as pessoas com necessidades especiais no dia-a-dia, pois as ruas e calçadas são muito irregulares, proporcionando difícil acesso.

Após a realização da performance pudemos conversar, contar o que cada uma tinha visto, ouvido, vivenciado, experimentado, percebido. A emoção era visível, estávamos todas muito entusiasmadas.

Ao final dessas experiências vivenciadas, as colaboradoras da pesquisa refletiram sobre como a proposta afetou a vida de cada uma delas, pensando no que contribuiu e de que forma as artes visuais passa a significar em sua formação docente.

Segundo as colaboradoras o corpo abordado na performance foi um corpo deficiente, com limitações, caracterizado pelo objeto/acessório que carregou consigo. Pensaram o corpo como algo que teve que se adaptar ao contexto, no caso delas ao corpo com alguma limitação física.

Elas pensam que além da teoria que vêem durante a graduação, precisam de outras vivências, de pensar a formação por outra perspectiva. Percebem que na verdade elas não estão ali para passar uma matéria, um reforço. Mas para encontrar meios de fazer com que crianças ou adultos com algum tipo de necessidade especial venham a se relacionar melhor, passar por aquilo tudo que nós, considerados normais, passamos. Oportunizar o conhecimento a que nós temos acesso dentro das diferenças deles.

Sobre as contribuições da arte para sua formação docente uma das colaboradoras diz:

Foi tremenda, por exemplo, hoje a gente se encontra na arte contemporânea, né? E ela questiona muito esse negócio do belo, do aceito como normal, e ainda tem muito essa coisa das percepções de cada indivíduo. Pois cada um percebe de forma diferente, e tu já remete a essa coisa da educação especial, das diferenças. Por que não precisa estar no corpo a diferença, a arte traz isso de que cada um percebe de forma diferente.

Assim, a partir da proposta dessa pesquisa, as colaboradoras puderam vivenciar a diferença através de uma experiência e reflexão artística. Segundo elas, essa vivência diferencia a formação delas de suas demais colegas, pois elas puderam refletir, experimentar e vivenciar sobre o corpo deficiente através das artes visuais, o que contribuiu para a atuação futura neste contexto. 


\section{Enfim...}

Percebo que a experiência de aproximação com as artes visuais contribuiu na reflexão sobre a construção da subjetividade docente das colaboradoras. E, ainda, na forma como percebem a relação que será construída com os seus futuros educandos, pois como disse uma delas, "nos fez perceber a necessidade de olhar nos olhos deles". Acredito que a partir do momento em que as colaboradoras dessa pesquisa refletiram sobre a diferença como algo presente em todos nós, seja no corpo, no modo de pensar, agir e se organizar, torna-se mais fácil compreender que na educação não existem "receitas", mas modos de se construir conhecimentos com os nossos educandos a partir do contexto de cada um.

Pensar o corpo e a arte no diálogo com o campo da formação docente, atrelado a questão da diferença e da educação especial, instaurou-se como via de acesso em discussões presentes no campo de atuação profissional, bem como enquanto indivíduos que fazem parte da sociedade contemporânea que tanto fala em inclusão pela diferença.

Refletir sobre as formas de apresentação do corpo a partir da perspectiva da cultura visual proporcionou as colaboradoras uma aproximação com a arte e um momento de interrupção no cotidiano acadêmico, pois foi um espaço de interação entre visualidades e vida cotidiana, possibilitando a reflexão sobre a formação docente numa perspectiva contemporânea da arte na educação. Tendo em vista que esta não corresponde apenas ao aprendizado de técnicas, mas, principalmente por meio da contextualização com o indivíduo e a arte, através da experiência vivencial, propondo uma educação de conhecimentos interligados e complexos, que eduque para a vida. Complexo, deve ser entendido aqui, do ponto de vista que nos coloca Oliveira (2009, p.217): "como um fenômeno possível, porém que exige de nós esforço nas reflexões, nas relações cognitivas, evitando o senso comum, o pensamento simplista, reducionista".

Desta forma, enquanto educadora neste espaço de educação compartilhada, pude possibilitar a construção de narrativas, onde as colaboradoras realizaram a "bricolagem de imagens, pensamentos, gestos e afetos, desafogando olhares e remexendo modos de ver, refletir, sentir e agir" (MARTINS; TOURINHO, 2009, p. 11). Uma forma de confrontar posições e oferecer outros percursos, desacomodando conceitos muitas vezes instituídos pelo hábito ou rotina.

Foi nessa busca por articulações entre educação das artes visuais, cultura visual, corpo e formação docente que desenvolvi esta pesquisa. Desarticular o papel da arte na 
educação como um passatempo, uma terapia, um dom, e propor um olhar ampliado, aberto, que a torne possível de ser pensada e problematizada em outras áreas do conhecimento. Pensando, dessa forma, a cultura visual e as artes como implicadas com o contexto social, histórico e cultural.

Comecei a trilhar o meu caminho enquanto arte/educadora, uma docência artista ${ }^{8}$ em que eu assumo o papel de um rascunho, de rabiscar, de ir e vir, de questionar e principalmente de partilhar, pois a educação só acontece a partir dessa troca onde se torna necessário abrir-se para as mudanças.

Destarte, desejo seguir (re)construindo minhas visões de mundo, preferencialmente sobre a educação e as relações que a partir dela acontecem. Gosto de pensar sobre a forma como as subjetividades e as narrativas são construídas a partir da cultura visual, especialmente na formação docente, sentindo-me nesse "entre lugar", onde o particular e o coletivo constroem-se mutuamente o tempo inteiro.

\section{Referências}

BARBOSA, Ana Mae. Tópicos Utópicos. Belo Horizonte: C/Arte, 1998. 200p.

BARBOSA, Ana Mae (org.). Inquietações e mudanças no ensino de arte. 2. ed. São Paulo: Cortez, 2003. 184p.

BHABHA, Homi K. O local da cultura. Belo Horizonte: Ed. UFMG, 1998. 394p.

CANTON, Katia. Narrativas enviesadas. São Paulo: Editora WMF Martins Fontes, 2009. $64 p$.

CHIZZOTTI, Antonio. Pesquisa em ciências humanas e sociais. 2. ed. São Paulo: Cortez, 1998. 165p.

COCCHIARALE, Fernando. Quem tem medo da arte contemporânea. Recife: Fundação J oaquim Nabuco, Editora Massangana, 2006. 76p.

DELEUZE, Gilles. Empirismo e subjetividade: ensaio sobre a natureza humana segundo Hume. Tradução de Luiz B. L. Orlandi. São Paulo: Ed. 34, 2001. 160p.

FREITAS, Soraia Napoleão. Sob a ótica da diversidade e da inclusão: discutindo a prática educativa com alunos com necessidades educacionais especiais e a formação docente. In: FREITAS, Soraia Napoleão (org). Tendências contemporâneas de inclusão. Santa Maria: Ed. da UFSM, 2008. pp. 19-30.

GREINER, Christine. O corpo: pistas para estudos indisciplinares. 3. ed. São Paulo: Annablume, 2008. 150p.

\footnotetext{
${ }^{8}$ Docência artista segundo Loponte (2007, p. 237) é "uma experiência de docência que não seja apenas aquilo que passa, que toca, que acontece, mas uma experiência que, enfim, nos passe, nos toque, nos aconteça".
} 
HERNÁNDEZ, Fernando. Para a Erina ninguém diz nada... E nós não podemos fazer o que queremos: A educação da cultura visual na educação infantil. In: MARTINS, Raimundo; TOURINHO, Irene (orgs). Cultura visual e infância: quando as imagens invadem a escola. Santa Maria: Ed. da UFSM, 2010. pp. 71-85.

LARROSA BONDÍA, Jorge. Notas sobre a experiência e o saber da experiência. Revista Brasileira de Educação. n. 19, Jan/Fev/Mar/Abr, 2002. pp. 20-28.

LOPONTE, Luciana Gruppelli. Arte da docência em arte: desafios contemporâneos. In: OLIVEIRA, Marilda Oliveira de (org). Arte, educação e cultura. Santa Maria: Ed. da UFSM, 2007. pp. 231-249.

MARTINS, Alice Fátima. Da educação artística à educação para a cultura visual: Revendo percursos, refazendo pontos, puxando alguns fios dessa meada... In: MARTINS, Raimundo; TOURINHO, Irene (orgs). Educação da cultura visual: narrativas de ensino e pesquisa. Santa Maria: Ed. da UFSM, 2009. pp. 101-117.

MARTINS, Raimundo; TOURINHO, Irene (orgs). Educação da cultura visual: narrativas de ensino e pesquisa. Santa Maria: Ed. da UFSM, 2009. 272p.

MESQUITA, Cristiane. Moda Contemporânea: quatro ou cinco conexões possíveis. São Paulo: Anhembi Morumbi, 2004. 128p.

OLIVEIRA, Marilda Oliveira de. O papel da Cultura Visual na formação inicial em Artes Visuais. In: MARTINS, Raimundo; TOURINHO, Irene (orgs). Educação da cultura visual: narrativas de ensino e pesquisa. Santa Maria: Ed. da UFSM, 2009. pp. 213-224.

ROSA, Aline Nunes da. Narrativas fílmicas e educação da artes visuais - percursos, afetos e bricolagens na formação inicial de professores. 163f. Dissertação (Mestrado em Educação) - Universidade Federal de Santa Maria, Santa Maria, 2010. 163p.

SILVA; Tomaz Tadeu da (org.). I dentidade e diferença: a perspectiva dos estudos culturais. Petrópolis, RJ: Vozes, 2000. 133p.

\section{Referências Digitais}

ANA MENDIETA. http://www.virginiamiller.com/exhibitions/1990s/AnaMendieta.html

BENETON. http://boquiaberto.wordpress.com/2009/03/30/a-classica-campanha-

benetton/

CINDY SHERMAN. http://www.cindysherman.com/art.shtml

CLAUDIA CASARINO. http://claudiacasarino.com/index.html

EUNICE ORLAN. http://omnia-mecum-porto.blogspot.com/2009/01/em-2009.html

LILLY MCELROY. www.lillymcelroy.com

LORETTA LUX. http://www. lorettalux.de/

NAZARETH PACHECO.

http://www. muvi.advant.com.br/artistas/n/nazareth_pacheco/nazareth pacheco.htm http://www.muvi.advant.com.br/artistas/n/nazareth_pacheco/nazareth_pacheco.htm

RODRIGO BRAGA. http://www.rodrigobraga.com.br/ 
RON MUECK. http://bethccruz. blogspot.com/2009/08/obras-ron-mueck.html VANESSA BEECROFT. http://www.vanessabeecroft.com 